\title{
THE JAPANESE CRANES OF HOKKAIDO
}

(Grus japonensis)

By Dr. T. H. BassetT

In December, 1962, during a brief stay in Japan I visited the north island of Hokkaido in order to see the Japanese Cranes which are carefully preserved near the seaport of Kushiro. A forty minute bus ride takes you to the nature park where five cranes which have been pinioned are enclosed in an area of grass and brushwood enclosed by a high fence. Another forty minutes by bus takes you further up the river valley to the neighbourhood of the small town of Akan. On farms in this area I saw thirty-three of the wild cranes. A recent census put the total for the whole crane population at 186 birds for the whole island.

At the farm where these birds are fed regularly I was able to film twenty of them as the farmer and his two small children threw maize and corn cobs to them from their buckets. The children everywhere play an active part in the conservation of the cranes. When the census project was first started in 1953 only some thirty primary and junior high schools in Kushiro Province took part in the investigation. But in 1960 as many as 8,000 pupils of eighty schools in the four provinces of Kushiro, Nemuro, Tokachi and Hidaka worked together and the census was carried out simultaneously throughout the provinces. This census is carried out each year early in December exactly at 10 a.m. on the same day everywhere. The pupils record the number of cranes, the direction of their flight and whether they are young or adult birds. In 1960 three small airplanes of the Ground Self Defence Force were also used to cover areas of swamps which were inaccessible to the pupils. The children also co-operate in purchasing maize for feeding the cranes and in making stacks of corn cobs at suitable places to enable the birds to feed during periods of snow and cold weather. It is very obvious that these measures are having a good effect, as the birds can be seen quite easily from the bus as it proceeds along the main road.

I was told that the breeding habitat of the cranes in the large swamps was not endangered by drainage operations at present. But I did see ditch digging in progress in a swampy area half-way between Kushiro and the crane park. Of course there are other swamps to which they fly in the summer-time for breeding which I did not see. These are safe for the time being in a country as densely populated as Japan it is impossible to feel sure that the swamps are safe for all time. However, the present protective measures are adequate and local interest and feeling towards the cranes could not be better. The birds only migrate locally to the big swamps. This makes their conservation easier than it is with some other species of cranes.

Note: James C. Greenway, Jr., in Extinct and Vanishing Birds of the World, referring to Grus japonensis as the Manchurian Crane writes-"Small populations are known to breed only in the marshes bordering Lake Khanka, Siberia, about 120 miles north of Vladivostok, and perhaps in isolated pairs along the Ussuri River and Amur River to its lower reaches. In Japan a very few are resident in a marsh near Kushiro, in eastern Hokkaido."- $E d$. 